Brazilian Journal
of Chemical
Engineering

ISSN 0104-6632

Printed in Brazil

www.abeq.org.br/bjche

Vol. 25, No. 03, pp. 461 - 471, July - September, 2008

\title{
RHEOLOGICAL CHARACTERIZATION OF CHICORY ROOT (CICHORIUM INTYBUS L.) INULIN SOLUTION
}

\author{
J. T. C. L. Toneli ${ }^{1,2^{*}}$, K. J. Park ${ }^{1}$, J. R. P. Ramalho ${ }^{3}$, F. E. X. Murr ${ }^{3}$ and I. M. D. Fabbro ${ }^{1}$ \\ ${ }^{1}$ School of Agricultural Engineering, State University of Campinas, UNICAMP, Phone: +(55) (19) 3521-1104, \\ Fax: +(55) (19) 3521-1005, P. O. Box 6011, CEP: 13084-971, Campinas - SP, Brazil. \\ E-mail: juliana@agr.unicamp.br, E-mail: juliana.toneli@ufabc.edu.br,E-mail: kil@agr.unicamp.br \\ ${ }^{2}$ Center of Engineering, Modeling and Applied Social Sciences, Federal University of ABC, \\ UFABC, Rua Catequese 242, CEP: 09090-400, Santo André - SP, Brazil. \\ ${ }^{3}$ School of Food Engineering, State University of Campinas UNICAMP, P. O. Box 6121, \\ CEP: 13083-970, Campinas - SP, Brazil.
}

(Received: March 1, 2007 ; Accepted: September 3, 2007)

\begin{abstract}
Inulin is a polysaccharide frequently used as a sugar or fat replacer in the food industry, which offers the advantage of a functional effect similar to those of dietary fibers. By cooling or freezing an inulin concentrated solution, a more concentrated solution precipitates as a paste-like substance, while the liquid phase forms a diluted solution. In this work, the effect of storage temperature of inulin concentrated solution as well as temperature on the rheological behavior of liquid and precipitated phases obtained from a process of phase separation were evaluated. The precipitated phase of inulin was evaluated under two conditions: pure and formulated with encapsulating agents. It was observed that a reduction in storage temperature resulted in a higher inulin precipitation, which produced higher apparent viscosity values for the precipitated phase. All the samples analyzed had a shear-thinning rheological behavior.

Keywords: Extraction; Cooling; Encapsulation; Viscosity; Mathematical model.
\end{abstract}

\section{INTRODUCTION}

Inulin is a polysaccharide found in more than 30,000 plants, which is composed of a chain of fructose units with a terminal glucose unit (Silva, 1996). One of these vegetable species, chicory roots, has been used for commercial production of inulin in Belgium, Holland and France. The reasons for choosing chicory are related to the production of stable long-chain glucose and fructose as well as its ready availability throughout the year, even in moderate climates.

Inulin is largely used by food industries in Europe, USA and Canada due to its capacity to substitute for sugar and fat to lower the calories count. For this reason, inulin has been used as an ingredient of light, diet and low-fat products. Besides inulin's ability to substitute for fat and sugar with no caloric contribution during the digestive process, it affects digestive physiological parameters in a way similar to dietary fibers. The ingestion of inulin results in a significant increase in beneficial bifido bacteria (Silva, 1996). Due to these properties, inulin can be classified as a functional ingredient.

Inulin is soluble in water with solubility dependent on temperature. At $10^{\circ} \mathrm{C}$, its solubility is about $6 \%$, whereas at $90^{\circ} \mathrm{C}$, it is about $35 \%$ (Silva, 1996). Kim et al. (2001) report that at $25^{\circ} \mathrm{C}$ inulin is almost insoluble in water, but its solubility increases significantly with increasing temperature. Due to its low solubility at low temperatures, when an inulin concentrated solution is cooled or frozen it undergoes a process of phase splitting. While a more concentrated phase precipitates as a pasty substance

*To whom correspondence should be addressed 
(precipitated phase), the other phase remains in suspension as a diluted solution (liquid phase).

Berghofer et al. (1993) observed that when an unstirred concentrated inulin solution ( $40 \%$ by weight) was cooled from 95 to $4^{\circ} \mathrm{C}$ over 30 hours, some of the inulin precipitated or crystallized as a pasty substance that could be removed by filtration. Hébette et al. (1998) reported that when concentrated solutions (30$45 \%$ by weight) of inulin are cooled at $1^{\circ} \mathrm{C} / \mathrm{min}$ or $0.25^{\circ} \mathrm{C} / \mathrm{min}$ from $96^{\circ} \mathrm{C}$ to $20^{\circ} \mathrm{C}$, suspensions of semicrystalline material are formed in water.

Kim et al. (2001) reported that an inulin gel could be made by shearing or heating/cooling an inulin suspension. According to these authors, heating of inulin suspension solubilized inulin and cooling caused precipitation of dissolved inulin. For gel made with this heating-cooling process, the ratio of gel to total volume is a function of heating temperature, inulin concentration, $\mathrm{pH}$ and solvent added.

Inulin is generally sold in powder form due to its easier handling, transportation and storage. Park et al. (2000) proposed a method for obtaining inulin concentrated solution by hot water extraction followed by concentration under reduced pressure with subsequent precipitation by cooling or freezing the inulin concentrated extract. To obtain the inulin in powder form, the concentrate obtained from the precipitation process is spray-dried.

The spray-drying of inulin can be carried out with two forms of the product: pure or formulated with encapsulating agents, which have the function of improving inulin's shelf life and some of its physical properties, such as hygroscopicity, solubility and flow.

Knowledge of the rheological behavior of liquid foods is essential for equipment projects as well as for evaluation of process conditions. Besides these, viscosity is a very important parameter in quality control and for consumer acceptance of the product.

According to Zimeri and Kokini (2003), although the nutritional properties of inulin have been thoroughly studied, its physicochemical properties and interactions with other food biopolymers have just begun to be characterized. These authors studied the rheological properties of mixed systems of inulin and waxy maize starch and observed the existence of a yield stress from steady shear data for concentrated inulin samples (30 and $40 \%$ by weight) through fitting the data to the Herschel-Bulkley equation. Nogueira (2001), Paoletti et al. (2001) and Bishay (1998) also studied the rheological behavior of solutions prepared with inulin and other polysaccharides.

Bot et al. (2004) studied the large-deformation rheology of inulin gels in terms of solubility, crystallization and aggregation data and observed that more concentrated inulin gels tend to be firmer, but also less plastic. A strong overshoot peak in the stress-strain curve, characteristic of work-softening behavior, characterizes the inulin gels. The authors hypothesized that the inulin molecules deposited during the later stages of the crystallization/gelation process contribute most to the overshoot peak in the stress-strain curve.

The main objective of this work was to evaluate the effect of storage temperature $(8$, -11 and $-15^{\circ} \mathrm{C}$ ) of an inulin concentrated solution extracted from chicory roots on the flow curves of the liquid and precipitated phases obtained from the separation process. The precipitated inulin was evaluated under two conditions: pure and formulated with encapsulating agents (hydrolyzed starch and modified starch). The flow curves were determined at three temperatures: 25,40 and $50^{\circ} \mathrm{C}$.

\section{METHODS AND MATERIAL}

\section{Inulin Extraction and Precipitation Procedures}

The steps involved in the inulin extraction and precipitation process are specified on Figure 1. The procedure is according to the method proposed by Park et al. (2000).

After harvest, chicory roots were washed with high-pressure water jet, sliced, milled and conducted to the extraction process. Inulin was extracted from chicory roots (Cichorium intybus) by diffusion in hot water at $80^{\circ} \mathrm{C}$ during 1 hour, with constant agitation. The obtained solution was concentrated until $24^{\circ} \mathrm{Brix}$ through an evaporation process at $70^{\circ} \mathrm{C}$ with a vacuum of $57.6 \mathrm{kPa}$. The concentrated solution was then submitted to a lowering temperature process, with the objective of obtaining phases separation. Three storage temperatures were evaluated:

- $8^{\circ} \mathrm{C}(\mathrm{T} 1)$, corresponding to a common domestical refrigerator temperature;

- $-11^{\circ} \mathrm{C}(\mathrm{T} 2)$, corresponding to a freezing temperature of a domestical freezer;

- $-15^{\circ} \mathrm{C}(\mathrm{T} 3)$, corresponding to a freezing temperature of a professional horizontal freezer.

The cooled solution was kept at $8^{\circ} \mathrm{C}$ during 42 hours, considered enough for a clear phases separation avoiding material fermentation. Frozen solutions kept at -11 and $-15^{\circ} \mathrm{C}$ were defrosted at room temperature $\left(25^{\circ} \mathrm{C}\right)$. Afterwards, the solutions were kept in a refrigerator at $8^{\circ} \mathrm{C}$ for 42 hours to eliminate the time factor influence, as well as to provide a better distinction between phases. The liquid and precipitated phases were separated manually, by simply pouring the liquid phase to another container. 


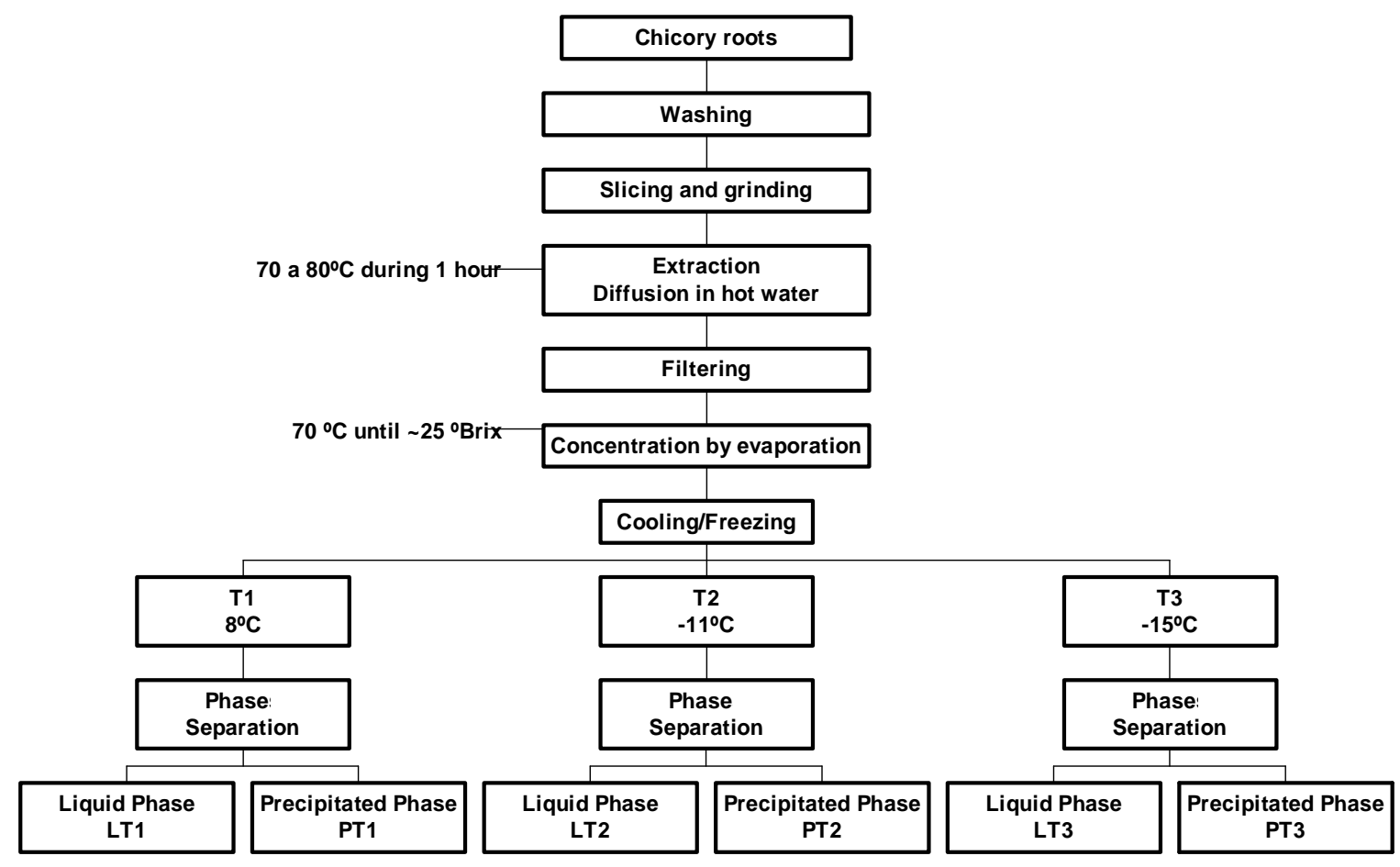

Figure 1: Inulin's extraction and precipitation processes.

\section{Formulation with Encapsulating Agents}

The precipitated phase obtained from the phases separation process was formulated with encapsulating agents for the evaluation of the rheological behavior of the resultant suspension. The encapsulating agents applied were: Loremalt 2002, a hydrolyzed starch, and Dextrina 17, a modified starch, both supplied by Cia. Lorenz. The applications were made at the ratio of $7.5 \%$ (in weight) of each ingredient, in accordance with the recommendations of Nogueira (2001).

\section{Determination of Soluble and Total Solids Concentration}

The official methodology of moisture determination, as described by the Association of Official of Analytical Chemists (1995) for sugars and sugar products, has been adopted for the determination of total solids concentration. Samples were dried for 24 hours with forced circulation oven at $100^{\circ} \mathrm{C}$. The soluble solids concentration was determined in an Abbé refractometer according to the Instituto Adolfo Lutz (1976) method no 13,6,1,5.

\section{Determination of Inulin Concentration}

The inulin concentration at the liquid and precipitated phases was determined through HPLC analysis with Aminex columns HPX-87c $(250 \mathrm{~mm} x$ $4 \mathrm{~mm}$ ), a refractive index Waters model 410 detector and a LCHE Waters model M-45 pump. Water was taken as the mobile phase at a ratio of $0.3 \mathrm{ml} / \mathrm{min}$, with an injected volume of 20 liters. The temperature of the column was set at $80^{\circ} \mathrm{C}$ and at $40^{\circ} \mathrm{C}$ for the detector. The concentration quantification was based on inulin standards prepared with Fluka sample (Bio Chemika).

\section{Rheological Analysis}

The rheological characterization of the samples was carried out at the following experimental conditions:

- Liquid phases obtained at $8^{\circ} \mathrm{C}$ (LT1), $-11^{\circ} \mathrm{C}$ (LT2) and $-15^{\circ} \mathrm{C}$ (LT3);

- Precipitated phases obtained at $8^{\circ} \mathrm{C}(\mathrm{PT} 1),-11^{\circ} \mathrm{C}$ (PT2) and $-15^{\circ} \mathrm{C}(\mathrm{PT} 3)$;

- Suspensions of inulin precipitated phases obtained at $8^{\circ} \mathrm{C}$ (MPT1), $-11^{\circ} \mathrm{C}(\mathrm{MPT} 2)$ and $-15^{\circ} \mathrm{C}$ 
(MPT3), formulated with encapsulating agents.

The flow curves were determined at controlled shear rate equipments. In all cases the shear rate was varied from a minimum up to a maximum value (increasing shear rate) and, after that, back from the maximum to the minimum (decreasing shear rate). All the rheological analyses were carried out at three temperatures: 25,40 and $50^{\circ} \mathrm{C}$.

\section{a) Liquid Phase}

The rheological properties of the liquid phase were evaluated with a digital rheometer Brookfield model LVDV-III series RP66567 with a sensor SC418 connected to a Rheocalc 32, version 2.3 by Brookfield Engineering Laboratories data acquisition system registering shear rate, apparent viscosity and shear stress. A Brookfield bath with a digital thermostat control model TC-501d was applied to set the sample temperature variation. Spindle rotation was set to vary from 105 to $200 \mathrm{rpm}$, generating shear rate values ranging from 139 to $264 \mathrm{~s}^{-1}$.

\section{b) Precipitated Phase}

The apparent viscosity of the pure and formulated precipitated phases was evaluated with a Rotating Rheometer CV20N Haake Fisons. The phenomenon associated to the flow between two parallel plates was explored connecting a PQ30 sensor on the stationary board maintaining rotating the second board. The gap between the plates was of $1.0 \mathrm{~mm}$. The shear rates remained between 0.000 and $200,000 \mathrm{~s}^{-1}$.

\section{Mathematical Modeling}

The mathematical analysis of the rheograms obtained from the analyzed samples was made by dividing these curves into two distinct parts. The first one, up-curve, describes the variation of the tension for the increasing shear rates. The second one, downcurve, describes the variation of the tension for the decreasing shear rates.

Through Statistica 5.0 software, the mathematical models were applied to the experimental data, resulting in an equation and in a theoretical curve relating the shear rate to the estimated shear stress corresponding to each model. The mathematical model analysis that best fits the experimental data was made through the calculation of the average relative error. These models were considered to exhibit a good fit if the relative error was maintained at values lower than $10 \%$.

The rheological behavior of the samples was characterize by Ostwald De Waele (Power Law), Herschel-Bulkley and Casson mathematical models, represented by equations (1), (2) and (3), respectively.

Power Law:

$$
\tau=\mathrm{K} \dot{\gamma}^{\mathrm{n}}
$$

Herschel-Bulkley:

$$
\tau-\tau_{0}=\mathrm{K}_{\mathrm{H}} \dot{\gamma}^{\mathrm{n}}
$$

Casson:

$$
\tau^{1 / 2}=\tau_{0}+\mathrm{K}_{\mathrm{C}} \dot{\gamma}^{1 / 2}
$$

\section{RESULTS AND DISCUSSION.}

\section{Determination of Soluble Solids and Total Solids}

Soluble solids measurement results, corrected by temperature, and total solids average values of the liquid, pure precipitated and formulated precipitated phases obtained under different conditions are presented in Table 1.

In Table 1 it can be observed that the liquid phase obtained from the solution stored at $8^{\circ} \mathrm{C}$ (LT1) had higher soluble solids rates than the LT2 and LT3 samples. A probable reason for this would be the low solubility of inulin at low temperatures, which did not allow migration of soluble solids to the liquid phase when the frozen samples were defrosted.

The higher total solids concentration in the LT1 sample than those in the LT2 and LT3 samples shows that the process of freezing the concentrated inulin solution is more efficient for attaining the precipitated phase than the cooling process.

\section{Determination of Inulin Concentration}

The average inulin concentration values for the liquid and precipitated phases, obtained under different conditions, are presented in Table 2. The values were corrected in accordance with the total solid corresponding to each one of the solutions, as shown in Table 1. The concentration was expressed in grams of inulin per grams of dry substance. 
Table 1: Total solids and soluble solids concentrations.

\begin{tabular}{|l|c|c|}
\hline Sample & $\begin{array}{c}\text { Soluble solids } \\
\left({ }^{\mathbf{B}} \mathbf{B r i x}\right)-\mathbf{2 0}{ }^{\circ} \mathbf{C}\end{array}$ & Total solids(w/w) \\
\hline LT1 & 18.50 & 0.2310 \\
LT2 & 14.00 & 0.1368 \\
LT3 & 13.75 & 0.1353 \\
PT1 & 16.15 & 0.3279 \\
PT2 & 16.12 & 0.3242 \\
PT3 & 16.40 & 0.3294 \\
MPT1 & 28.58 & 0.4078 \\
MPT2 & 27.61 & 0.4017 \\
MPT3 & 28.83 & 0.4071 \\
\hline
\end{tabular}

Table 2: Inulin concentration on a dry basis for liquid and precipitated phases.

\begin{tabular}{|l|c|}
\hline Sample & Average inulin concentration $(\mathbf{w} / \mathbf{w})$ \\
\hline LT1 & 0.2175 \\
LT2 & 0.0480 \\
LT3 & 0.0723 \\
PT1 & 0.5153 \\
PT2 & 0.5820 \\
PT3 & 0.7826 \\
\hline
\end{tabular}

The values presented in Table 2 show that of the liquid phases, the LT1 sample had the highest inulin concentration, which was as much as 4.5 times the LT2 value and 3 times the LT3 sample value. Therefore, regarding the liquid phases, the simple cooling of the sample was not enough to remove a higher amount of inulin from the solution. In accordance with the data on inulin concentration in the precipitated phase, the clear effect of temperature can be observed with the lower freezing temperature resulting in a larger inulin sample concentration.

\section{Flow Curve Evaluation}

\section{Effect of Inulin, Soluble Solids and Total Solids Concentrations}

Figure 2 and Figure 3 contain the flow curves obtained at $25^{\circ} \mathrm{C}$ for all inulin precipitated phase samples (PT1, PT2 and PT3) and for all inulin liquid phase samples (LT1, LT2 and LT3), respectively.

In observing Figure 2, it can be noted that the PT1 sample had the lowest apparent viscosity values, while the PT2 and PT3 samples showed flow curves that were practically coincident. In Figure 3, however, the opposite behavior can be observed: the LT1 sample had the highest apparent viscosity values, as much as 2.5 times the apparent viscosity values of the LT3 sample. The LT2 and LT3 samples had flow curves that were almost coincident.

A comparison of the results presented in Figures 2 and 3 with data shown in Table 3 shows that higher values of inulin, soluble solids and total solids concentration result in higher apparent viscosity values at a temperature of $25^{\circ} \mathrm{C}$. This trend was also observed at temperatures of 40 and $50^{\circ} \mathrm{C}$. However, for inulin precipitated samples, which are more concentrated, a reduction in this trend with increasing temperature was observed. The apparent viscosity value of the PT1 sample was as low as 0.66 times the apparent viscosity value of the PT2 sample at $25^{\circ} \mathrm{C}$. This value went up to 0.73 at $40^{\circ} \mathrm{C}$ and to 0.83 at $50^{\circ} \mathrm{C}$.

Ginner et al. (1996) evaluated the effect of temperature and concentration on the rheological behavior of cherry juice and observed that as the temperature increased, the apparent viscosity of the juice decreased. However, for higher concentrations of soluble solids, the authors observed the opposite effect of temperature on apparent viscosity. In studying the rheology of clarified and non clarified lemon products, Saenz and Costel (1986) observed that in the presence of pulp and pectins, the effect of temperature on the rheological behavior of the products was reduced. 


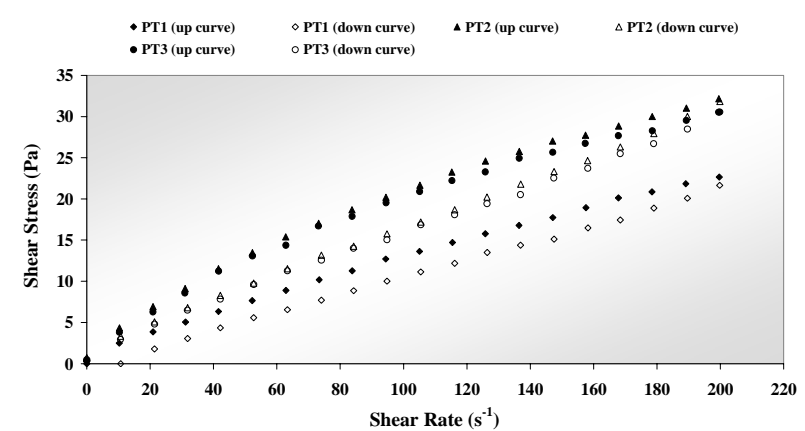

(a) Rheogram

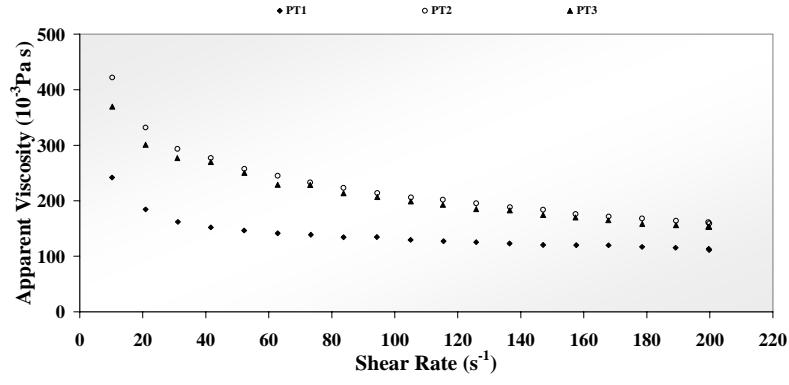

(b) Apparent Viscosity (Up curve)

Figure 2: Flow curve of inulin precipitated phase samples obtained at $25^{\circ} \mathrm{C}$.

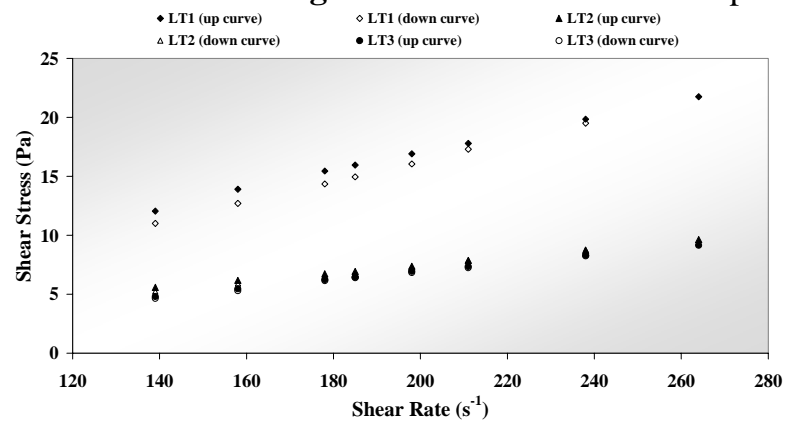

(a) Rheogram

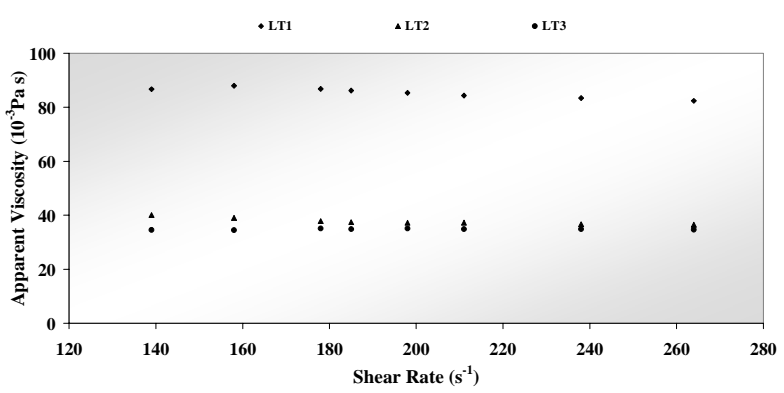

(b) Apparent Viscosity (Up curve)

Figure 3: Flow curve of inulin liquid phase samples obtained at $25^{\circ} \mathrm{C}$.

According to the results, the apparent viscosity of the precipitated phase was higher than that of the liquid phase, for all temperatures evaluated. However, the difference between the apparent viscosity values of the samples was higher for the PT3 and LT3 samples. At $50^{\circ} \mathrm{C}$, values for the apparent viscosity of the PT3 sample were as much as 8 times the apparent viscosity value of the LT3 sample. Otherwise, at the same temperature, the PT1 sample had apparent viscosity values as high as 1.8 times the apparent viscosity value of the LT1 sample.

According to data presented in Tables 1 and 2, the inulin liquid phase sample obtained at $8^{\circ} \mathrm{C}$ (LT1) had the highest values of inulin, soluble solids and total solids concentrations. Otherwise, the inulin precipitated sample obtained under the same conditions (PT1) had the lowest values of inulin, soluble solids and total solids concentrations. These results confirm the trend of increasing apparent viscosity of the samples with increasing concentrations of inulin, total solids and soluble solids.

\section{Effect of Addition of Encapsulating Agents}

Figure 4 contains the flow curves for the PT1 and MPT1 samples at temperatures of 25,40 and $50^{\circ} \mathrm{C}$. In Figure 4, it can be observed that the addition of encapsulating agents caused an increase in apparent viscosity, as expected. This trend was also observed for the PT2 and PT3 samples.

The difference between the apparent viscosities of pure and formulated precipitated phases was smaller for low shear rates with a trend to increase with higher shear rates. The apparent viscosity increased from 2 to 3.7 times with addition of the encapsulating agents. This increase can be explained by the higher total and soluble solids concentrations in the samples, generated by the addition of encapsulating agents.

Bishay (1998) studied the interaction of 35\% inulin gel with other hydrocolloids. He did not observe any significant interaction between the soluble hydrocolloids studied and inulin. However, the system of $35 \%$ inulin gel with $10 \%$ unmodified starch gel had negative synergy, probably due to the affinity for water. The addition of unmodified starch to inulin gel resulted in a lower overall viscosity and weaker gel strength.

In observing Figure 4, one can perceive that for the PT1 and MPT1 samples, the apparent viscosity decreased with increasing temperature. However, it can be noted that the addition of encapsulating agent had a greater effect on the extent of the difference between apparent viscosities than temperature, i.e., the effect of temperature difference on apparent viscosity was more insignificant than the effect of addition of formulating components for the interval considered. This behavior was even observed for the 
PT2 and PT3 samples when formulated with encapsulating agents. These results agree with those reported by Nogueira (2001) for chicory root inulin extracts formulated with wall material concentrations varying from 5 to $30 \%$.

\section{Mathematical Analysis}

Mathematical analysis of the flow curves obtained for all the samples was carried out using the Ostwald de Waele (PL), Herschel Bulkley (HB) and Casson (Ca) models. All the models evaluated offered a good fit; however, the Herschel Bulkley and Casson models were considered physically inadequate, since the yield stress had negative values.

The empirical parameters obtained from the fit of data to the power law model are shown in Table 3. The corresponding average relative errors are presented in Table 4. According to the values presented in Tables 3 and 4, the power law model

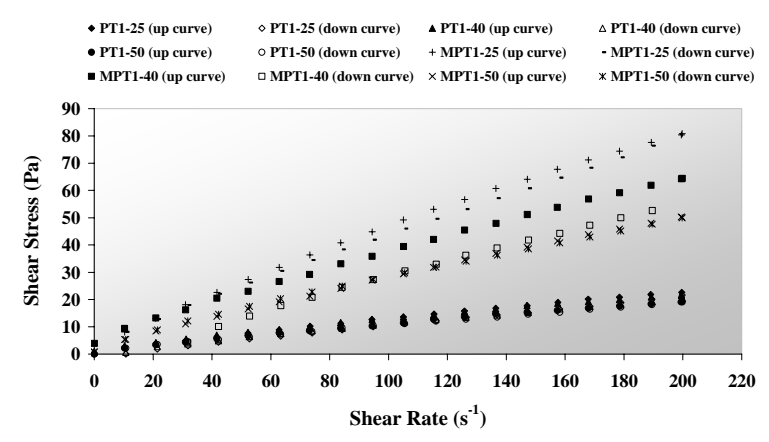

(a) Rheogram offered a good fit, since the $\mathrm{R}^{2}$ values are close to 1.0 and the average relative error values are lower than $10 \%$. Figures 5, 6 and 7 illustrate the graphic fit for the liquid, pure precipitated and formulated precipitated phases, respectively.

The flow index values of the liquid phase presented in Table 3 show that all the samples, except the LT3 sample evaluated at $25^{\circ} \mathrm{C}$, have slightly pseudoplastic behavior during the up curve. During the down curves, however, almost all the flow index values were higher and some samples were found to be Newtonian or even awkwardly dilatant. These results indicate that the rheological behavior of the inulin liquid phase is slightly thyxotropic, mainly for the LT1 sample, which had higher soluble solids and inulin concentrations. For all the liquid phase samples, the rheological behavior became more pseudoplastic with the increase in temperature, as is normally expected for biological products.

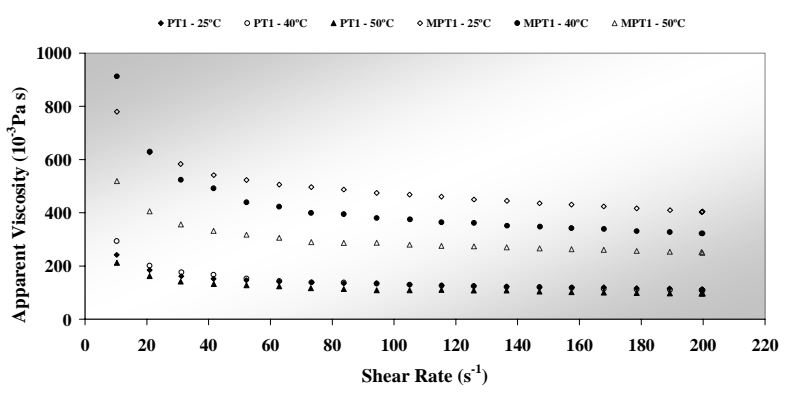

(b) Apparent Viscosity (Up curve)

Figure 4: Flow curves for pure (PT1) and formulated (MPT1) inulin precipitated samples, obtained at temperatures of 25,40 and $50^{\circ} \mathrm{C}$.

Table 3: Theoretical parameters of the mathematical models employed in determination of the rheological behavior of the precipitated phase.

\begin{tabular}{|c|c|c|c|c|c|c|c|c|c|c|c|}
\hline \multirow{2}{*}{ Sample } & \multirow{2}{*}{$\begin{array}{l}\mathbf{T} \mathbf{v}^{\mathbf{a}} \\
\left({ }^{\circ} \mathbf{C}\right)\end{array}$} & \multirow{2}{*}{$\mathbf{D}^{\mathbf{b}}$} & \multicolumn{3}{|c|}{ Liquid Phase } & \multicolumn{3}{|c|}{ Precipitated Phase } & \multicolumn{3}{|c|}{ Encapsulated } \\
\hline & & & K & n & $\mathbf{R}^{2}$ & $\mathbf{K}$ & $\mathbf{n}$ & $\mathbf{R}^{2}$ & $\mathbf{K}$ & $\mathbf{n}$ & $\mathbf{R}^{2}$ \\
\hline \multirow{6}{*}{1} & \multirow{2}{*}{25} & Up & 0.150 & 0.893 & 0.9993 & 0.335 & 0.800 & 0.9996 & 1.186 & 0.798 & 0.9998 \\
\hline & & Down & 0.060 & 1.057 & 0.9999 & 0.173 & 0.915 & 0.9992 & 0.948 & 0.835 & 0.9995 \\
\hline & \multirow{2}{*}{40} & $\mathbf{U p}$ & 0.127 & 0.869 & 0.9998 & 0.450 & 0.733 & 0.9993 & 1.224 & 0.747 & 0.9991 \\
\hline & & Down & 0.056 & 1.016 & 0.9998 & 0.325 & 0.787 & 0.9989 & 1.420 & 0.715 & 0.9984 \\
\hline & \multirow{2}{*}{50} & Up & 0.174 & 0.777 & 0.9910 & 0.297 & 0.787 & 0.9993 & 0.642 & 0.823 & 0.9997 \\
\hline & & Down & 0.071 & 0.936 & 0.9995 & 0.271 & 0.800 & 0.9991 & 0.790 & 0.780 & 0.9997 \\
\hline \multirow{6}{*}{2} & \multirow{2}{*}{25} & Up & 0.074 & 0.871 & 0.9987 & 1.04 & 0.648 & 0.9991 & 0.983 & 0.813 & 0.9999 \\
\hline & & Down & 0.042 & 0.974 & 0.9986 & 0.308 & 0.869 & 0.9983 & 0.869 & 0.831 & 0.9996 \\
\hline & \multirow{2}{*}{40} & $\mathbf{U p}$ & 0.028 & 0.964 & 0.9996 & 0.614 & 0.703 & 0.9991 & 0.703 & 0.827 & 0.9998 \\
\hline & & Down & 0.038 & 0.908 & 0.9993 & 0.283 & 0.841 & 0.9988 & 0.831 & 0.791 & 0.9995 \\
\hline & \multirow{2}{*}{50} & Up & 0.118 & 0.675 & 0.9891 & 0.315 & 0.775 & 0.9995 & 0.734 & 0.812 & 0.9996 \\
\hline & & Down & 0.091 & 0.722 & 0.9958 & 0.373 & 0.738 & 0.9992 & 1.205 & 0.717 & 0.9997 \\
\hline \multirow{6}{*}{3} & \multirow{2}{*}{25} & Up & 0.035 & 1.000 & 0.9996 & 1.004 & 0.647 & 0.9983 & 1.035 & 0.787 & 0.9998 \\
\hline & & Down & 0.028 & 1.041 & 0.9995 & 0.307 & 0.862 & 0.9985 & 0.714 & 0.852 & 0.9996 \\
\hline & \multirow{2}{*}{40} & Up & 0.044 & 0.872 & 0.9991 & 0.997 & 0.655 & 0.9992 & 0.939 & 0.807 & 0.9998 \\
\hline & & Down & 0.037 & 0.904 & 0.9994 & 0.294 & 0.876 & 0.9987 & 0.667 & 0.866 & 0.9995 \\
\hline & \multirow{2}{*}{$\mathbf{5 0}$} & Up & 0.072 & 0.748 & 0.9956 & 0.628 & 0.723 & 0.9984 & 1.096 & 0.793 & 0.9999 \\
\hline & & Down & 0.064 & 0.765 & 0.9967 & 0.183 & 0.948 & 0.9994 & 0.814 & 0.843 & 0.9994 \\
\hline
\end{tabular}

${ }^{\mathrm{a}}$ Temperature of viscosity determination; ${ }^{\mathrm{b}}$ Path of the increasing (up curve) or decreasing (down curve) deformation rate 
Table 4: Average relative error of the mathematical models employed in determination of the rheological behavior.

\begin{tabular}{|c|c|c|c|c|c|}
\hline \multirow{2}{*}{ Sample } & \multirow{2}{*}{$\mathbf{T v}$} & \multirow{2}{*}{ D } & \multicolumn{3}{|c|}{ Average Relative Error (\%) } \\
\hline & & & $\mathbf{P}$ & $\mathbf{L}$ & MP \\
\hline \multirow{6}{*}{$\mathbf{T 1}$} & \multirow[b]{2}{*}{$25^{\circ} \mathrm{C}$} & Up & 1.77 & 0.62 & 1.25 \\
\hline & & Down & 2.45 & 0.25 & 2.12 \\
\hline & \multirow{2}{*}{$40^{\circ} \mathrm{C}$} & Up & 1.93 & 0.26 & 2.85 \\
\hline & & Down & 2.71 & 0.33 & 3.07 \\
\hline & \multirow{2}{*}{$50^{\circ} \mathrm{C}$} & Up & 2.11 & 1.80 & 1.96 \\
\hline & & Down & 2.98 & 0.56 & 1.25 \\
\hline \multirow{6}{*}{$\mathbf{T 2}$} & \multirow[b]{2}{*}{$25^{\circ} \mathrm{C}$} & Up & 2.22 & 0.79 & 0.71 \\
\hline & & Down & 4.17 & 0.93 & 2.03 \\
\hline & \multirow{2}{*}{$40^{\circ} \mathrm{C}$} & Up & 1.82 & 0.49 & 1.29 \\
\hline & & Down & 3.04 & 0.58 & 1.84 \\
\hline & \multirow{2}{*}{$50^{\circ} \mathrm{C}$} & Up & 1.80 & 1.74 & 2.21 \\
\hline & & Down & 2.05 & 1.06 & 1.31 \\
\hline \multirow{6}{*}{$\mathbf{T 3}$} & \multirow{2}{*}{$25^{\circ} \mathrm{C}$} & Up & 3.38 & 0.52 & 1.07 \\
\hline & & Down & 3.37 & 0.70 & 2.00 \\
\hline & \multirow{2}{*}{$40^{\circ} \mathrm{C}$} & Up & 2.21 & 0.54 & 1.13 \\
\hline & & Down & 2.98 & 0.59 & 2.14 \\
\hline & \multirow{2}{*}{$50^{\circ} \mathrm{C}$} & Up & 2.79 & 1.17 & 0.85 \\
\hline & & Down & 2.21 & 1.04 & 2.29 \\
\hline
\end{tabular}

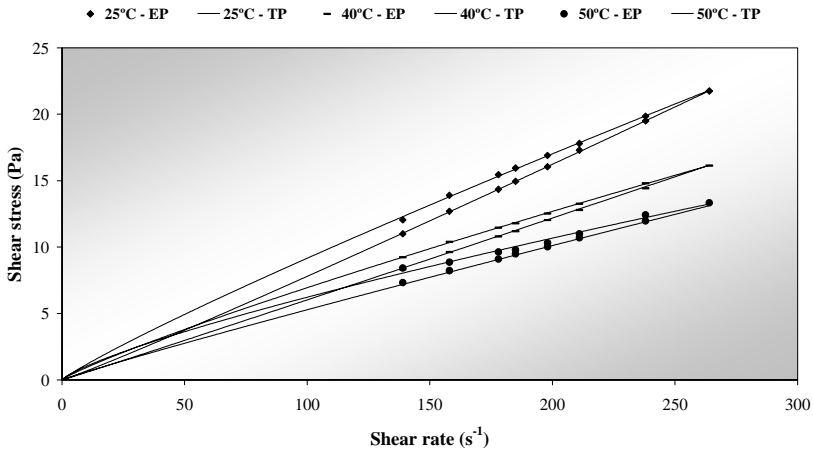

(a) LT1

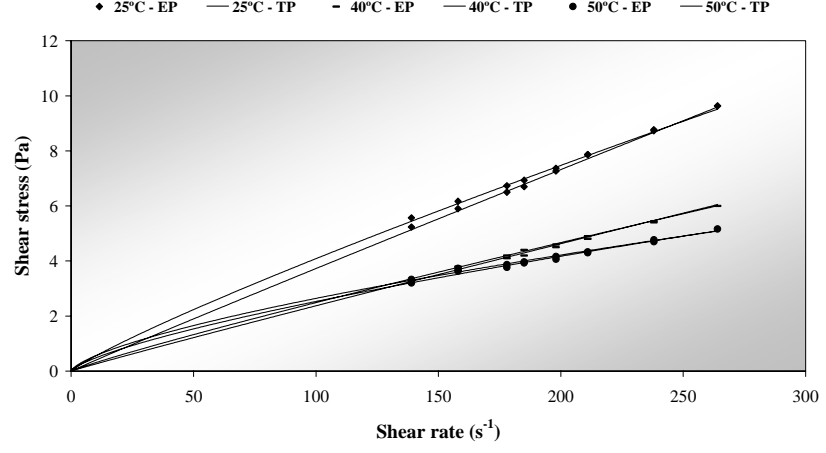

(b) LT2

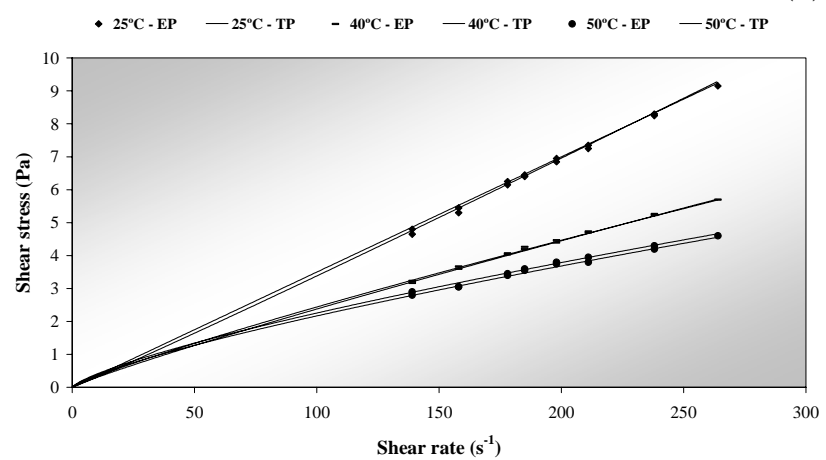

(c) LT3

Figure 5: Rheograms for the liquid phases, evaluated in accordance with the power law mathematical model 


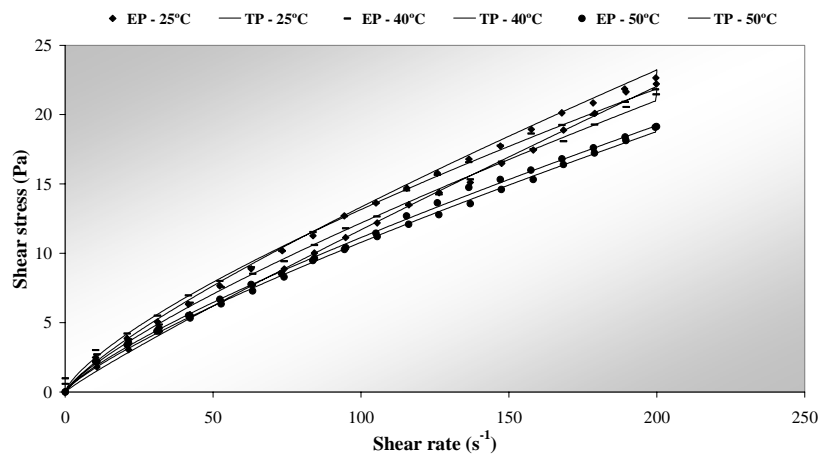

(a) PT1

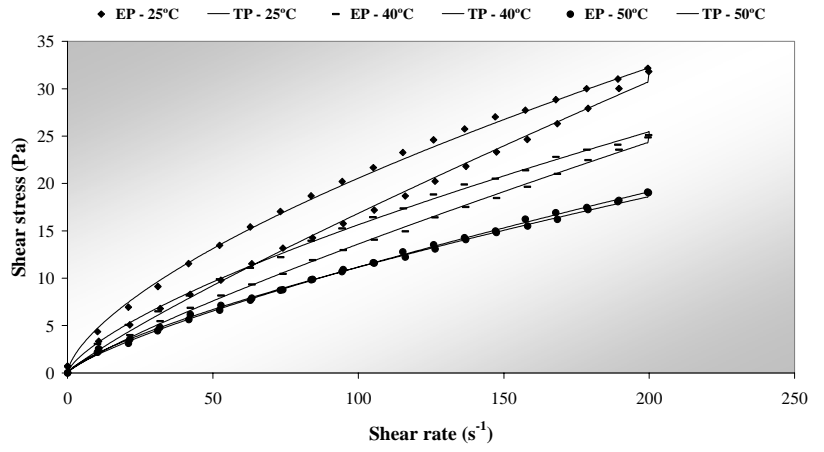

(b) PT2

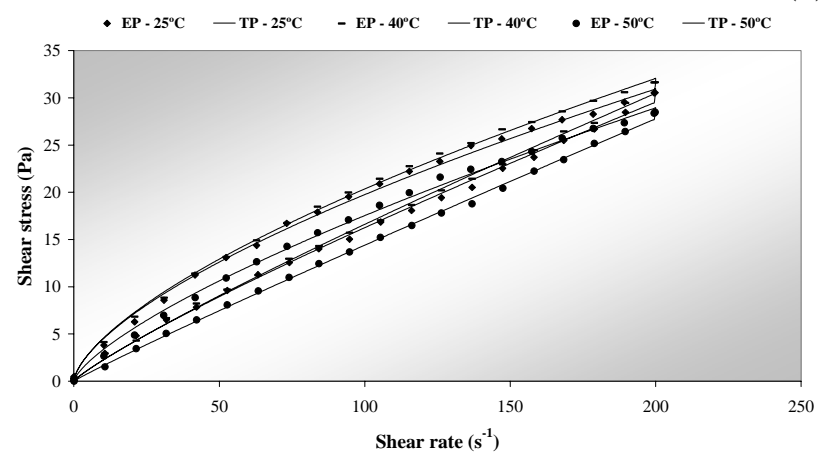

(c) PT3

Figure 6: Rheograms for the pure precipitated phases, evaluated in accordance with the power law mathematical model

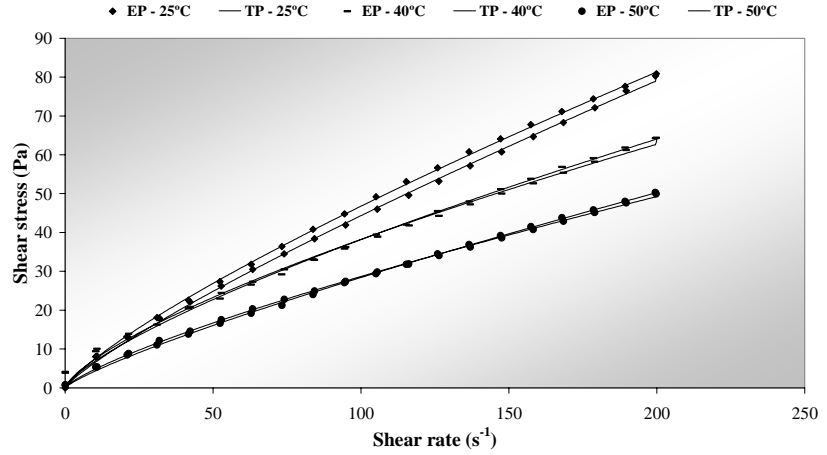

(a) MPT1

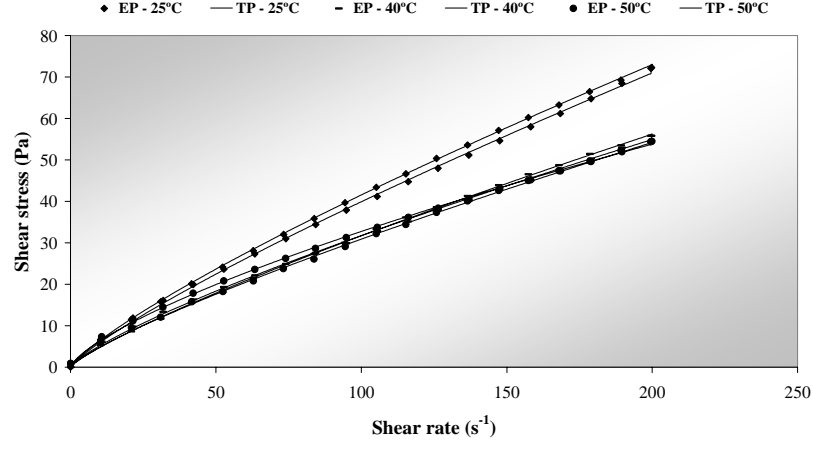

(b) MPT2

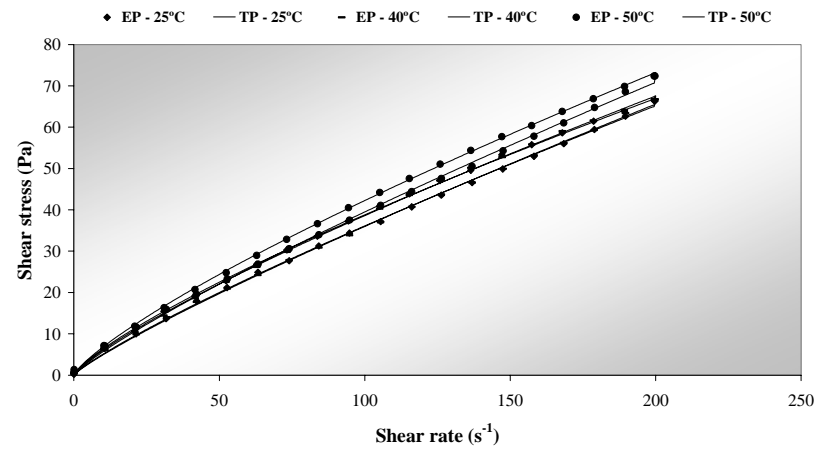

(c) MPT3

Figure 7: Rheograms for the formulated precipitated phases, evaluated in accordance with the power law mathematical model 
The results presented in Table 3 show that all the precipitated samples, whether encapsulated or not, had pseudoplastic behavior with flow index values varying between 0.655 and 0.948 . During the down curves, almost all the flow index values were higher for pure precipitated samples, which indicates that they had a slightly thyxotropic behavior that was more pronounced for the samples evaluated at room temperature $\left(25^{\circ} \mathrm{C}\right)$. The precipitated samples obtained at $-15^{\circ} \mathrm{C}$ had the most evident thyxotropic behavior for all the evaluation temperatures.

By observing the results in Table 3 it can be noted that the evaluation temperature had just a small effect on the flow index of the precipitated samples, mainly after addition of the encapsulating agents. Besides that, the addition of encapsulating agents reduced the thyxotropic behavior of all the precipitated samples. These results support the conclusion that the addition of encapsulating agents resulted in a precipitated inulin solution with more stable rheological properties.

By considering the results obtained for the flow index of liquid and precipitated phases, one can conclude that the increase in inulin concentration produced more structured solutions with thyxotropic and pseudoplastic behaviors. In observing Figures $2 b$ and $4 \mathrm{~b}$ it can be noted that the behavior of the apparent viscosity of inulin precipitated samples, both pure and formulated with encapsulating agents, was of a shear-thinning material at low strain rates. For higher strain rates, the behavior was close to being linear.

These results are in accordance with those presented by Bot et al. (2004), Zimeri and Kokini (2003), Nogueira (2001) and Bishay (1998). All these authors studied the rheological behavior of inulin solutions and found that, at high inulin concentrations, they have a shear-thinning behavior of a very structured fluid. BISHAY (1998) reported that at $15 \%$ solids and below, inulin displays Newtonian behavior of typical soluble, lowmolecular-weight systems. However, at $25 \%$ solids and above, inulin begins to display strong shearthinning behavior.

In Figure 3b, it can be seen that the behavior of the apparent viscosity of liquid phase samples was close to being linear. Considering that these rheograms were determined for strain rates from 139 to $264 \mathrm{~s}^{-1}$ it is reasonable to suppose that, for lower strain rates, the samples would have the shearthinning behavior, predicted by the power law model.

\section{CONCLUSIONS}

Results of the present work show that the inulin concentration in the precipitated samples increased with decreasing storage temperature of the concentrated inulin solution.

Rheological analysis showed that the liquid phase samples and the inulin precipitated samples, either pure or formulated with encapsulating agents, had the rheological behavior of a non-Newtonian fluid with shear-thinning features for temperatures of 25 , 40 and $50^{\circ} \mathrm{C}$. It was also observed that apparent viscosity tends to increase with increasing inulin concentration for both liquid and precipitated phases. The effect of wall material on the formulated extract viscosity was greater than that of temperature.

The Ostwald-of-Waele (power law) mathematical model is the most appropriate for representing the experimental data obtained from the rheological analysis of the liquid, pure precipitated and formulated precipitated phases, carried out at temperatures of 25,40 and $50^{\circ} \mathrm{C}$.

\section{ACKNOWLEDGMENTS}

We acknowledge the financial support received from The State University of Campinas (UNICAMP), The State of São Paulo Research Foundation (FAPESP), The National Council for Scientific and Technological Development (CNPq) and Coordenação de Aperfeiçoamento de Pessoal de Nível Superior (CAPES).

\section{NOMENCLATURE}

$\begin{array}{ll}\text { Ca } & \begin{array}{l}\text { Casson Model } \\ \text { Path of the increasing (up } \\ \text { curve) or decreasing (down } \\ \text { curve) deformation rate }\end{array} \\ \mathrm{D} & \begin{array}{l}\text { Herschel Bulkley Model } \\ \mathrm{HB}\end{array} \\ \mathrm{K} & \begin{array}{l}\text { Consistency index } \\ \text { Casson consistency index }\end{array} \\ \mathrm{K}_{\mathrm{C}} & \begin{array}{l}\text { Herschel-Bulkley } \\ \text { consistency index }\end{array} \\ \mathrm{K}_{\mathrm{H}} & \begin{array}{l}\text { Liquid phase obtained at a } \\ \text { temperature of } 8^{\circ} \mathrm{C}\end{array} \\ \mathrm{LT} 1 & \begin{array}{l}\text { Liquid phase obtained at a } \\ \text { temperature of }-11^{\circ} \mathrm{C}\end{array} \\ \text { LT2 } & \begin{array}{l}\text { Liquid phase obtained at a } \\ \text { temperature of }-15^{\circ} \mathrm{C}\end{array} \\ \text { LT3 }\end{array}$
$(\text { Pas })^{\mathrm{n}}$ $(\mathrm{Pas})^{1 / 2}$ 
Precipitated phase obtained

MPT1 at a temperature of $8^{\circ} \mathrm{C}$, formulated with encapsulating agents Precipitated phase obtained

MPT2 at a temperature of $-11^{\circ} \mathrm{C}$, formulated with encapsulating agents Precipitated phase obtained

MPT3 at a temperature of $-15^{\circ} \mathrm{C}$, formulated with encapsulating agents

n Flow index

PL Power law model

PT1 Precipitated phase obtained at a temperature of $8^{\circ} \mathrm{C}$

PT2 Precipitated phase obtained at a temperature of $-11^{\circ} \mathrm{C}$

PT3 Precipitated phase obtained

$\mathrm{R}^{2} \quad$ at a temperature of $-15^{\circ} \mathrm{C}$

$\mathrm{R}^{2} \quad$ Correlation coefficient

T1 Temperature of $8^{\circ} \mathrm{C}$

T2 Temperature of $-11^{\circ} \mathrm{C}$

T3 Temperature of $-15^{\circ} \mathrm{C}$

$\mathrm{Tv}$

$(-)$

${ }^{\circ} \mathrm{C}$ determination

\section{Greek Letters}

$\begin{array}{ll}\tau & \text { Shear stress } \\ \tau_{0} & \text { Yield stress } \\ \dot{\gamma} & \text { Shear rate }\end{array}$

\section{REFERENCES}

Association of Official Analytical Chemists, Official methods of analysis of A.O.A.C. international. 16th ed. Arlington: A.O.A.C., Inc. (1995).

Berghofer, E.; Cramer, A.; Schmidt, V.; Veigl, M., Pilot-scale production of inulin from chicory roots and its use in foodstuffs. In: FUCHS, A. (Ed). Inulin and inulin-containing crops. Elsevier Science, Amsterdam (1993).

Bishay, I. E., Rheological characterization of inulin. In: Williams, P. A.; Phillips, G. O. (Eds.) Gums and stabilizers for the food industry. vol. 9, Royal Society of Chemistry, London (1998).

Bot, A.; Erle, U.; Vreeker, R., Agterof, W. G. M., Influence of crystallization conditions on the large deformation rheology of inulin gels. Food Hydrocolloids, 18, No. 4, 547-556 (2004).

Ginner, J.; Ibarz, A.; Garza, S.; Xhian-Quan, S., Rheology of clarified cherry juices. Journal of Food Engineering, 30, No. 1/2, 147-154 (1996).

Hébette, C. L. M.; Delcour, J. A.; Koch, M. H. J., Complex melting of semi-crystalline chicory (Cichorium intybus L.) root inulin. Carbohydrate Research, 310, No. 1-2, 65-75 (1998).

Instituto Adolfo Lutz, Normas analíticas do Instituto Adolfo Lutz. Vol. 1 (1976).

Kim, Y.; Faqih, M. N.; Wang, S. S., Factors affecting gel formation of inulin. Carbohydrate Polymers, 46, No. 2, 135-145 (2001).

Nogueira, R. I., Processo de obtenção de inulina de chicória (Cichorium intybus) em pó. Ph.D. diss., Faculdade de Engenharia Agrícola, Universidade Estadual de Campinas (2001)

Paoletti, F.; Nardo, N.; Monici, M.; Maini, S.; Butturini, A., Caratterizzazione reologica di miscele di inulina com fibre. Industrie Alimentari, 40, No. 404, 633-635 (2001).

Park, K. J.; Park, T. H. K. B.; Park, K. J. B.; Nogueira, R. I.; Leite, J. T. C., Processo de obtenção de concentrado de inulina por abaixamento de temperatura e separação física. BR Patente número PI 0003867-9 (2000).

Silva, R.F., Use of inulin as a natural texture modifier. Cereal Foods World, 41, No. 10, 792795 (1996).

Saenz, C.; Costel, E., Comportamiento reológico de productos de limón. Influência de la temperatura y de la concentración. Revista de Agroquimica y Tecnología de Alimentos, 26, No. 4, 581-588 (1986).

Zimeri, J. E.; Kokini, J. L., Rheological properties of inulin-waxy maize starch systems. Carbohydrate Polymers, 52, No. 1, 67-85 (2003). 